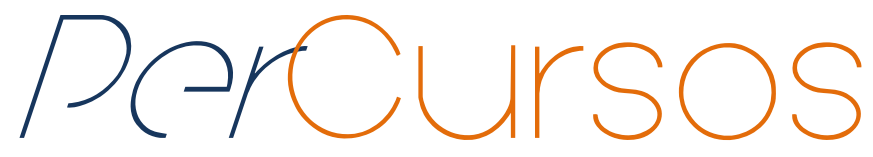

\title{
Escrita, linguagem e memória: as condições de possibilidade da (in)diferença entre sujeito e objeto ${ }^{1}$
}

\begin{abstract}
Resumo
O artigo analisa as condições de possibilidade da (in)diferença entre sujeito e objeto a partir de três instrumentos basilares das ciências humanas: escrita, linguagem e memória. Para tanto, elege-se o vínculo entre os teóricos da Escola de Frankfurt, aqui representados por Theodor Adorno, a perspectiva reacionária da historiografia, com Jacques Le Goff e Edward Carr, e o construto teórico pósestruturalista de Jacques Derrida. O escopo do trabalho fundamentase no ponto de convergência que esses teóricos possuem - a crítica ao positivismo metafísico e à racionalidade instrumental. Para tentar cumprir esse propósito, propõe-se no primeiro momento a apresentação da indecidibilidade da escrita/escritura na análise derridiana do discurso social; logo após, averigua-se, com o auxílio dos escritos adornianos, a posição da linguagem em relação à memória no discurso da tradição racionalista e, finalmente, apresenta-se a definição de memória na perspectiva da ciência histórica contemporânea, ressaltando seu aspecto burocratizado e burocratizante na esfera social.
\end{abstract}

Palavras-chave: Escritura; Linguagem; Memória; Sujeito e objeto.

\author{
Cleyton Murilo Ribas \\ Doutorando em Sociologia e \\ História da Educação na \\ Universidade Federal de Santa \\ Catarina. Professor do Instituto \\ Federal de Santa Catarina - \\ Campus Jaraguá do Sul - Brasil. \\ cleytonribas@gmail.com
}

\section{Para citar este artigo:}

RIBAS, Cleyton Murilo. Escrita, linguagem e memória: as condições de possibilidade da (in)diferença entre sujeito e objeto. Revista PerCursos. Florianópolis, v. 15, n.29, p. 103 -121. jul./dez. 2014.

\section{DOI: 10.5965/1984724615292014103}

http://dx.doi.org/10.5965/1984724615292015103

\footnotetext{
${ }^{1} \mathrm{O}$ presente texto constitui um desdobramento da pesquisa de doutorado sobre a continuidade teórica e argumentativa dos instrumentos conceituais da Teoria Crítica nos ditames do Pós-estruturalismo français, marcadamente caraterizados pela ruptura com o sistema lógico da modernidade.
} 


\title{
Writing, language and memory: the conditions of possibility of (in) difference between subject and object
}

\begin{abstract}
The article analyzes the conditions of possibility of (in) difference between subject and object from three basic tools of the humanities: writing, language and memory. To do so, elect up the link between the theorists of the Frankfurt School, represented here by Theodor Adorno, reactionary perspective of historiography, with Jacques Le Goff and Edward Carr, the theoretical and poststructuralist Jacques Derrida construct. The scope of work is based on the convergence point that these theorists have - the critique of metaphysical positivism and instrumental rationality. To try to fulfill that purpose, it is proposed at first presentation of the undecidability of writing / writing in Derrida's analysis of social discourse; soon after it ascertains-with the aid of Adorno written, the position of language in relation to memory in the speech of the rationalist tradition, and finally presents the memory setting from the perspective of contemporary historical science, stressing its bureaucratic and bureaucratizing aspect in the social sphere.This paper is an offshoot of a PhD research on theoretical and argumentative continuity of conceptual tools of Critical Theory dictates of Post-structuralism français markedly characterized by the break with the logical system of modernity..
\end{abstract}

Keywords: Scripture; Language; Memory; Subject and object. 


\section{Introdução: A deformação do discurso e a falência do sujeito burguês}

O presente artigo constitui um desdobramento do projeto de doutorado no Programa de Pós-Graduação em Educação da UFSC e é parte do programa de pesquisas Teoria Crítica, Racionalidades e Educação, cujo objetivo geral vem sendo, desde 2005 (em suas sucessivas etapas), avançar na consolidação de um programa de pesquisa que procura a reflexão sobre o legado e o potencial da Teoria Crítica da Sociedade da Escola de Frankfurt em sua dimensão pedagógica. Esse processo se coloca no duplo movimento que, simultaneamente, consolida e ultrapassa o plano disciplinar: o da investigação conceitual dessa tradição, movimento que tem trazido questões sempre novas a partir do esforço coletivo de muitos pesquisadores ao redor do mundo; o da iluminação de desafios contemporâneos para o campo da Educação, procurando colaborar para a consecução de uma Teoria Crítica do presente.

Tendo como ponto de partida que o século XX é demarcado por mudanças epistemológicas decisivas no campo das investigações das ciências humanas, percebe-se que a tradição moderna filosófica ditava as regras positivistas sacramentadas em seu próprio discurso metafísico, de outro, emergiam conflitos e antagonismos históricos e teóricos no processo de civilização dominante capitalista. As condições de possibilidade da ciência e do sujeito por ela constituído não representavam mais quesitos irrefutáveis na reflexão teórica. As reações ao discurso dominante foram estabelecidas em diferentes territórios do conhecimento, porém sustentaram aproximações notadamente complementares na denúncia do progresso científico e da razão dominadora.

Em uma entrevista cedida a Henri Ronse em 1972, Jacques Derrida problematiza uma das principais evidências epistemológicas da filosofia sobre a refutação da tradição racionalista, qual seja, a impossibilidade de eliminá-la por completo. A efetivação do discernimento e da interpretação do mundo encontra-se no reconhecimento e posterior enfrentamento das contradições da tradição.

Tento me manter no limite do discurso filosófico. Digo "limite" e não "morte", porque não creio, de forma alguma, naquilo que se chama, hoje, facilmente, de "morte da filosofia" (nem, aliás, na morte do que seja: o livro, o homem ou deus; tanto mais que, como todos sabem, o 
morto carrega uma eficácia bastante específica). Limite, pois, a partir do qual a filosofia se tornou possível, se definiu como episteme, funcionando no interior de um sistema de constrições fundamentais, de oposições conceituais fora das quais ela se torna impraticável. (DERRIDA, 2001, p. 12)

Segundo a ótica derridiana, o combate ao processo de alienação do sujeito das sociedades capitalistas liberais se estabelece pelo interesse nas forças agenciadas dentro do discurso falado e institucionalizado pela escrita. A perspectiva da desconstrução surge como uma abordagem ética da leitura e interpretação textual, subsidiando o desmantelamento das armações ontológicas tradicionais da razão centrada no sujeito.

$\mathrm{Na}$ mesma direção investigativa, porém cronologicamente anterior, pode-se encontrar um grupo de teóricos precursores da retomada da crítica marxista à estrutura monolítica da sociedade - o Instituto de Pesquisa Social. Fundado na década de 20, na cidade de Frankfurt, este agrupamento de intelectuais estabelecia uma tentativa de criar um novo paradigma capaz de repensar criticamente a vida social marcada pelos antagonismos do sistema capitalista. Dentro desta perspectiva, os escritos sobre a formação do sujeito político de Adorno ganham notoriedade na medida em que a educação é apresentada como processo emancipatório².

Além disso, evidencia-se também um terceiro movimento de teóricos sociais, no domínio da história, que orientaram suas pesquisas com o objetivo de suplantar os limites das orientações positivistas - a Escola dos Annales. Nesta escola, os estudos dirigiam-se para a incorporação das ciências sociais na História, ampliando a perspectiva científica com métodos pluridisciplinares. Os pesquisadores que dela fizeram parte representam uma renovação dos paradigmas da investigação histórica, rechaçando métodos tradicionais e promovendo uma perspectiva inovadora do conceito científico das humanidades. O papel do cientista nas humanidades é vinculado a diferentes áreas do conhecimento, fomentando o engajamento social que esse sujeito teleologicamente

\footnotetext{
${ }^{2}$ Emancipação é um conceito adorniano que se encontra na abordagem da constelação das noções básicas da educação do século XX, cujo propósito baseia-se no fato de Auschiwitz não se repetir. A busca pelo fim do escamoteamento das raízes fomentadoras da perseguição nazista, aliado ao compromisso teórico e prático da autodeterminação do sujeito em formação, proporciona o constante enfrentamento da barbárie, determinante social regente da ideologia totalitarista do período entre guerras (Adorno, 1995a).
} 
possui. Discussões sobre o método científico e definições basilares, tais como história e memória, foram refletidas e dispostas sob novo viés, o de promover condições epistemológicas e práticas de efetivação das investigações científicas de modo a promover condições significativas de mudanças sociais que não sejam pautadas na prática pura do método e de sua linguagem lógica, promovedores do esquecimento e da perpetuação dos regimes antagônicos do conhecimento.

Partindo desses três pilares - sociologia, história e filosofia - o presente trabalho busca analisar os papéis da escrita, da memória e da linguagem nas amarras estabelecidas nos parâmetros da identidade do sujeito moderno, pretensamente universal, padronizado em suas regras de conduta e direcionado pela noção de progresso científico idealizado. As críticas à exclusão do diferente inerente nos processos civilizatórios da razão instrumental e a defesa da multiplicidade das investigações nas ciências humanas, promovem a mobilidade e pluralidade interpretativa fortemente ligada à reflexão das ciências em geral. Para tanto, o presente artigo dividiu-se em três momentos: inicialmente, propõe-se a apresentação da indecidibilidade da escrita/escritura na análise derridiana do discurso social; em seguida, averigua-se, com o auxílio dos escritos adornianos, a posição da linguagem em relação à memória no discurso da tradição racionalista e, finalmente, apresenta-se a definição de memória no âmbito da ciência histórica contemporânea, ressaltando seu aspecto burocratizado e burocratizante na esfera social.

\subsection{Escrita, escritura e veneno: a farmacologia de Derrida}

A obra derridiana é marcada por um constante processo de desvelamento das tradições metafísicas que culminam na repressão logocêntrica ${ }^{3}$. Um dos aspectos determinantes da perspectiva teórica de Derrida constitui-se na negação de um conjunto limitado de conceitos. O arcabouço argumentativo baseia-se nos indecidíveis, operadores

\footnotetext{
${ }^{3}$ Logocentrismo constitui em um construto teórico derridiano que aponta para o fato da razão moderna ser, desde René Descartes, considerada o elemento potencial de excelência nas relações epistemológicas, formando no método científico as condições de repressão e imposição de sua lógica linguística (Derrida, 1991).
} 
de leitura que sinalizam os limites do discurso (Derrida, 1991). Tais operadores evitam que postulados sejam unificados em um significado universal, possibilitando a luta contra o domínio dos estereótipos e a tirania das normas.

Um dos indecidíveis que remete ao escopo do deste trabalho constitui o termo francês écriture, que na língua portuguesa pode corresponder a duas possibilidades de tradução: escrita e escritura. Ambas as traduções são importantes para a compreensão da abordagem tradicional do termo, e para a perspectiva proposta pelo autor francoargelino, para além dos limites da linguagem, considerada processo de criação.

Retomam-se os principais argumentos da obra “A farmácia de Platão”, publicada pela primeira vez em 1972, a fim de compreender a crítica da esfera da tradição da definição de escrita. Nesse livro, Derrida explica de que maneira a filosofia como área ampla do conhecimento se consolidou pelo discurso institucionalizado. Por meio do rebaixamento e da subordinação da escrita em prol do discurso falado (logos e fono), o teórico demonstra o modo pelo qual a tradição instituiu o fonologocentrismo da metafísica como sinônimo de verdade.

Sem dúvida, a ciência gramatical não é a dialética. Platão tende a subordinar a primeira à segunda (253 b c). E esta distinção é natural, segundo ele; mas o que a justifica em última instância? Ambas são, de certo modo, ciências da linguagem. Pois a dialética é também a ciência que nos guia "dià tôn lógon", através dos discursos ou argumentos (253 b). Nesse ponto, o que a distingue da gramática parece duplo: por um lado, as unidades lingüísticas das quais ela se ocupa são maiores que a palavra (Crátilo, 385 a -393 d); por outro lado, ela é sempre guiada por uma intenção de verdade; apenas pode suplantá-la a presença do eidos, que é aqui, ao mesmo tempo, o significado e o referente: a coisa mesma. A distinção entre gramática e dialética só pode, pois, estabelecer-se, com todo o rigor, no ponto em que a verdade está plenamente presente e preenche o logos. (DERRIDA, 2005, p. 120)

A presença da verdade aludida pela citação acima se refere ao que determina o personagem Sócrates sobre a questão da dialética e sua relação com a memória. Derrida retoma e analisa os diálogos platônicos com o objetivo de verificar o processo de consolidação dialética em detrimento da linguagem escrita, considerada pelo pai da filosofia como inferior e danificadora das potências filosóficas. Partindo principalmente 
do texto platônico Fedro, a escrita se delineia como representação fonética instituída e submissa ao discurso oralizado.

A contra-argumentação socrática de maior relevância na depreciação da escrita é vislumbrada pelo fato da mesma não representar uma forma autêntica da memória, mas um viés de esquecimento, signo da morte, pois repete sem saber (Derrida, 2005). A escrita é a simples representação da fala utilizada pelos menos favorecidos intelectualmente, incapaz de promover o diálogo, pois o autor do texto está ausente. A ausência é a morte do intelecto e a escrita, a imagem do homicida propriamente dito.

Sócrates, conhecido na história da filosofia como o sábio que nunca publicou uma obra escrita sequer, aponta a escritura no seu caráter dual - órfã de pai e ao mesmo tempo parricida, responsável pela ausência presente do logos. Assim, o termo phármakon surge como a definição mais apropriada para os signos da escrita, pois traduz a dualidade da droga: do remédio e/ou do veneno.

A escritura é o filho miserável. O miserável. O tom de Sócrates é tanto acusador e categórico, denunciando um filho desviado e revoltado, uma desmedida e uma perversão, tanto compadecido e condescendente, apiedando-se de um ser desguarnecido, um filho abandonado por seu pai. De qualquer modo, um filho perdido. Cuja impotência é tanto aquela de um órfão quanto a de um parricida perseguido, e, por vezes, injustamente. (DERRIDA, 2005, p. 97)

Nesse sentido, a farmácia de Platão representa o ordenamento do discurso legítimo, privilegiado pela fala e pela presença do pai-autor, único capaz de controlar a interpretação e promover a verdade no ordenamento logocêntrico. A presença daquele que elaborou o texto é idêntica ao próprio objeto produzido, incapaz de se desdobrar, fundamentando a metafísica da presença. A escritura é a potência do falso, cópia da verdade, incapaz de suportar a si mesma o logro interpretativo.

No momento em que Derrida aponta a escritura como indecidível, suspende-se a perspectiva limitante tradicional da escrita para a abertura exegética. Não há unidade ou sistematicidade no texto escrito, mas linhas que delimitam os discursos e as interpretações possíveis ou coerentes dos mesmos. O discurso socrático-platônico fundou a instituição filosófica metafísica, reduzindo o texto ao processo hermenêutico 
ortodoxo. Todo texto está condicionado ao processo ritualístico, o "rito do pharmakós: o mal e a morte, a repetição e a exclusão" (Derrida, 2005, p.85).

No entanto, não fica apenas a cargo da filosofia o processo de institucionalização metafísica da escrita. A religião, o direito e as ciências em geral estabelecem ordenamentos ideologicamente fundamentados na pretensiosa posse da verdade, do justo e do bom. Na obra publicada em 2001, "Papel-Máquina”, Derrida dialoga com Roger Chartier $^{4}$ a propósito da história tecnopolítica da escrita, questionando o processo de sacralização do livro e sua pseudocrise com o surgimento das versões virtuais das obras escritas.

Sobre a análise da era digital, o livro como obra é apresentado como fim, em dois sentidos "como morte e como telos ou realização" (Derrida, 2004, p. 30). Tal constatação está baseada na crítica às unidades de suporte do mundo - escrever e ler. O primeiro representa a unidade do discurso, o segundo a reverência às obras. Novamente, retoma-se a transposição identitária canonizada entre sujeito e objeto (autor e leitor), capaz de velar discursos e regramentos socialmente naturalizados. A disseminação do conhecimento verdadeiro, divinizado e voluntariamente disposto pela Natureza é, na contemporaneidade, resultado da WWW, "o livro de Deus, o grande livro da Natureza ou o Livro-Mundo em seu sonho onto-teológico enfim realizado" (Derrida, 2004, p. 31).

Outro exemplo da crítica derridiana à ambiguidade da razão instrumental é expresso no conceito de "différance". Na língua francesa, o termo correspondente para expressar o vocábulo diferença é "différence". O problema encontra-se na manifestação fonética, pois a troca "a" pela letra "e" realizada no neologismo de Derrida não interfere

4 No texto O mundo como representação (1991), Chartier posiciona-se acerca das teorias que enunciam a descontinuidade e discordância da escrita e de suas interpretações, na defesa da consideração dos discursos "em seus próprios dispositivos, suas articulações retóricas ou narrativas, suas estratégias de persuasão ou de demonstração" (p. 187). Segundo este autor, em tais abordagens epistemológicas, os agenciamentos do discurso possuem sua própria lógica, que podem caracterizar "mentalidade" (ou de uma " visão do mundo" ou de uma " ideologia"), ou mesmo uma consignação social unívoca (Chartier, 1991).

Ao contrário de Derrida e dos demais pensadores de maio de 68, a investigação de Chartier é diferenciada: "Nossa perspectiva é outra: quer compreender a partir das mutações no modo de exercício do poder (geradores de formações sociais inéditas) tanto as transformações das estruturas da personalidade quanto as das instituições e das regras que governam a produção das obras e a organização das práticas" (Chartier, 1991, p. 188). 
na língua falada, apenas no registro escrito. O equívoco fonético proposital inverte o valor da representação da fala pela escrita. A letra "a" não se ouve, permanece silenciosa, discreta e secreta. Como consequência, consolida-se a crítica ao aspecto fonético da gramática tradicional. O silêncio exigido pela estrutura da razão não possui sentido no discurso de neutralidade da ordem estabelecida.

Por analogia, a teoria da "différance" apregoa a impossibilidade do sujeito ser autor e senhor do discurso que produz 5 . Por conseguinte, com o mesmo motor crítico adorniano da incapacidade da experiência filosófica, o ato de definir um conceito, em Derrida, também se revela impossível. Todo discurso é heterônomo e predeterminado, aceito pelo interlocutor e reproduzido pelo comunicante. Tal polissemia inerente à interpretação textual individual carrega como consequência a efemeridade do conceito de identidade do sujeito. Desta maneira, "différance" constitui o ato de diferir de si, através do tempo, e de se diferenciar ou, até mesmo, de se opor ao outro em diversos desdobramentos sociais condicionados pelas determinações das estruturas e dos seus centros (Derrida, 2009).

Contudo, a imbricação das relações entre sujeito-objeto, linguagem oral e escrita, memória e esquecimento não constituem discussões originariamente derridianas. Na seção seguinte, apresenta-se a abordagem adorniana ${ }^{6}$ sobre a investigação suscitada, buscando apontar hipóteses das bases epistemológicas que promovem possíveis aproximações entre os argumentos críticos de Derrida e as disposições dialógicas do discurso metodológico nas ciências humanas.

\footnotetext{
5 "Nada - nenhum ente presente e indiferente [indidifférant] - precede, pois, a différance e o espaçamento. Não existe qualquer sujeito que seja agente, autor e senhor da différance, um sujeito ao qual ela sobreviria, eventualmente e empiricamente. A subjetividade - como a objetividade - é um efeito de différance, um efeito inscrito em um sistema de différance".(Derrida, 2001, p. 34)

6 Qualquer comparação realizada entre Derrida e Adorno demanda a referência do texto "Fichus: discours de Francfort", pronunciado no discurso de agradecimento que Derrida fez ao receber o prêmio Adorno. Nesse pronunciamento, Derrida cita um trecho da obra "Mínima Morália" para expor seu vínculo e sua herança recebida da teoria adorniana, baseada na descrença pelo projeto da modernidade e na premissa da necessidade da consciência reflexiva.
} 


\subsection{Linguagem e esquecimento na perspectiva adorniana}

Os escritos de Theodor Adorno são marcados pelo intenso processo de compreensão da sociedade industrial dilatada de modo desmedido e dos progressos do conhecimento positivo da natureza, proporcionados pela economia de mercado do capitalismo tardio (Adorno, 2009). A desproporção entre "poder e todas as formas de espírito" (ibidem, p. 11) resultou na incapacidade da compreensão daquilo que é sociologicamente predominante.

Os sistemas dominantes e suas ideologias baseadas no capitalismo são resultados dos escritos iluministas e do conceito de dialética hegeliano (Adorno, 1992). Esta dialética também é chamada de Dialética Positiva por Adorno, e visa à identidade do sujeito em relação ao objeto de modo sistemático e reducionista. Predicados como universal, identidade dos sujeitos sociais modernos, padronização dos costumes e a identificação dos mesmos com a coletividade limitam o potencial reflexivo à consciência coisificada e reduzem a filosofia a uma ciência particular. Desta forma, não há espaço para o heterogêneo nem para o diferente, que é violentado em uma lógica da exclusão.

Por sua vez, o teórico de Frankfurt apresenta sua própria dialética - a negativa fundamentada na consciência da não-identidade, destituída de qualquer natureza de síntese ou exclusão. A não-identidade como fundamento da Dialética Negativa preconiza um requisito teórico fundamental - a descaracterização do conceito como determinação de unidade. O pensamento não pode ser igual ao pensado em uma totalidade objetiva. $\mathrm{A}$ coisa em si não é idêntica ao seu conceito. Qualquer tentativa de tornar aparentemente idêntico conceito e objeto/ coisa e pensamento é ideológica.

Os conceitos, segundo Adorno, já estão implicitamente concretizados pela linguagem em que estão imersos. Assim, a neutralidade da linguagem como organização do pensamento é impossível. O pensamento por si mesmo passa a representar um contato com outros textos impostos na tradição, em uma metodologia de repetição e reprodução das estruturas lógicas já consolidadas pela exclusão e fomentação do poder. A linguagem em Adorno não é um ente autônomo, mas expressão das relações sociais (Adorno, 1992). 
A alternativa apresentada por Adorno para construir uma identidade social subjetiva e autônoma encontra-se no aparato individual da autorreflexão, referida como procedimento capaz de superar o paradoxo do conceito e do discurso reprodutório pretensamente objetivo e verdadeiro:

O trabalho da autorreflexão filosófica consiste em destrinçar tal paradoxo. Todo o resto é designação, pós-construção, hoje como nos tempos de Hegel algo pré-filosófico. Uma confiança como sempre questionável no fato de que isso é possível para a filosofia; no fato de que o conceito pode ultrapassar o conceito, os estágios preparatórios e o toque final, e, assim aproximar-se do não-conceitual: essa confiança é imprescindível para a filosofia e, com isso, parte da ingenuidade da qual ela padece. De outra forma, ela precisaria capitular, e, com ela, todo espírito. Não se poderia pensar a mais simples operação, não haveria nenhuma verdade, e, em um sentido enfático, tudo não seria senão nada. Todavia, aquela parte da verdade que pode ser alcançada por meio dos conceitos, apesar de sua abrangência abstrata, não pode ter nenhum outro cenário senão aquilo que o conceito reprime, despreza e rejeita. $\mathrm{A}$ utopia do conhecimento seria abrir o não-conceitual com conceitos, sem equipará-lo a esses conceitos. (ADORNO, 2009, p. 16-17)

O projeto da Dialética Negativa é, portanto, o reconhecimento que o discurso não tem condições de adequar-se ao seu objeto de modo transparente e neutro. Através desse procedimento negativo, figura-se a crítica à ideologia metafísica de dominação. Tal abordagem direciona-se sobre o que há de mais constitucional no contexto histórico da Teoria Crítica - o combate à reprodução de teorias, à massificação dos sujeitos e à repetição da barbárie desumanizadora, Auschwitz. Nesse ínterim, o processo educacional recebe uma consideração significativa, pois surge como única ferramenta efetiva contra o panorama totalitário exclusório do capitalismo. O ponto de convergência entre autorreflexão do sujeito e superação social da barbárie passa a possuir na autonomia do sujeito seu divisor de águas. O potencial formativo que a educação possui em Adorno baseia-se na capacidade da mesma de eliminar o silêncio sobre o terror das ditaduras e de sistemas de organização social baseados no universalismo identitário. A educação visa superar os ditames da linguagem objetivamente constituída e os meios de comunicação, pois ambos promovem a violência e a eliminação da diferença pelo intermédio da severidade e da reificação da consciência (Adorno, 1995a). 
Na obra Dialética do Esclarecimento, Adorno e Horkheimer pontuam que pelo apoderamento da natureza pelo ser humano, possibilitou-se a formação do sujeito moderno, egóico e individual (Horkheirmer; Adorno, 1985). Entretanto, tal domínio trouxe consequências pesarosas no processo de busca de sua autonomia. A separação sujeito e objeto, o esquecimento, a alienação e a posterior reificação passaram a constituir a tônica do processo formativo degradado (Adorno, 1991).

No aforismo intitulado "Le prix du progrès" que compõe a seção de Notas e Esboços da Dialética do esclarecimento, Adorno comenta sobre uma carta do fisiologista Pierre Flourens, transposta integralmente no texto, na qual o profissional da saúde explica que o enfraquecimento da memória é o principal efeito colateral da utilização do clorofórmio na prática de operações cirúrgicas. No fim de seu relato técnico, Florens levanta a questão "Não seria este (a perda da memória) um preço excessivamente alto a pagar pelo progresso?" (Adorno, 1985, p. 214). Para o teórico de Frankfurt, a resposta é absolutamente afirmativa, visto que a perda da lembrança é condição transcendental da ciência, a pulsão máxima da reificação como esquecimento.

A violência do esquecimento consubstancia o regresso ao mito, fundador do fetiche pelos símbolos. A memória passa a ser considerada coadjuvante, destituída de sentido e até mesmo pertencente ao discurso irracional na avaliação do discurso positivista.

A partir deste relacionamento com o tempo, a memória também adquire um status específico: ela passa a ser considerada como uma mera sobra sem sentido. "O que é o mesmo que dizer que a memória, o tempo e a lembrança são liquidados pela própria sociedade burguesa em seu desenvolvimento, como se fossem uma espécie de resto irracional". Trata-se de um processo análogo à "racionalização progressiva dos procedimentos da produção industrial que elimina junto aos outros restos da atividade artesanal também categorias como a da aprendizagem, ou seja, do tempo de aquisição da experiência do ofício". (ADORNO, 1995a, p. 33)

Adorno parte em defesa da afirmação da memória, viva em sua atualidade e denunciadora do terror, da violência e dos mecanismos de dominação. Os totalitarismos perdurarão e continuarão a repressão na medida em que a memória for negada. Lembrar 
significa assumir o erro e despender todas as forças para não repeti-lo, sejam nas macro ou nas microrrelações. O fascismo ganha sobrevida em toda tentativa de repressão linguística nomeada em nome da igualdade dos indivíduos e de suas constituições, de corpo, de objeto. O indivíduo não é, negativamente, idêntico a si mesmo, mas um complexo de contextos relacionais justapostos (JAY, 1988). A seção seguinte pretende evidenciar a retomada da noção de memória, mas agora no arcabouço epistemológico do historiador, vinculando as ciências humanas, especialmente História e Sociologia, na perspectiva crítica da tradição positivista.

\subsection{A memória histórica - A (co)memoração da simbologia do poder.}

O presente tópico tem como objetivo nodal tecer um paralelo entre as abordagens de dois historiadores contemporâneos - Edward Carr ${ }^{7}$ e Jacques Le Goff ${ }^{8}$ acerca da memória com os problemas epistemológicos da escritura derridiana e da linguagem em Adorno.

Um dos aspectos determinantes presente nas investigações historiográficas fundamenta-se na proposta do conceito de memória vinculada não apenas ao relato dos acontecimentos, mas proponente de uma postura questionadora do documento e das informações já institucionalizadas. A existência da imaginação do historiador, da sociedade e de suas implicações econômicas e políticas compõem o cerne do sistema histórico metodologicamente constituído como relevante ao cientista. A etnologia e a antropologia dialogam com o historiador em suas interpelações investigativas no enfrentamento da perspectiva positivista da ciência argumentativa.

Nos capítulos III e IV da obra “O que é história?” (1987), Carr desenvolve uma retomada cronológica crítica de diferentes metodologias científicas aplicadas em história demonstrando a impossibilidade do caráter estático e eterno de qualquer investigação. Para tanto, o autor direciona sua crítica ao tradicional conceito de leis presente nas

\footnotetext{
${ }^{7}$ Teórico inglês que foi diplomata e professor de relações internacionais, participante crítico da elaboração do Tratado de Versailles e simpatizante da política soviética do século XX.

8 Historiador francês especialista em história medieval, representa uma revolução metodológica na historiografia, principalmente como participante da terceira geração da Escola dos Annales.
} 
ciências naturais e deslocado às ciências humanas durante o predomínio positivista do discurso objetivamente válido. Aspectos como regularidade, explicação e previsão em história constituem cristalizações descabidas com o ofício científico do historiador (Carr, 1987). Este profissional trabalha com hipóteses que se abrem para novas investigações, calcadas em princípios de análise ou interpretação, distantes de qualquer univocidade do discurso preconizado em leis gerais.

Consequentemente, uma perspectiva hermenêutica é assumida. Parte-se do pressuposto de que todas as hipóteses são fragmentárias e dignas de exegese imparcial, porém não objetiva. A história é apresentada como ciência subjetiva, visto que o homem observa a si próprio (Carr, 1987). A impropriedade das leis faz do historiador um usuário de generalizações a fim de testar suas evidências. O processo de conhecimento demanda a inter-relação e a interdependência entre sujeito e objeto de análise. As ciências sociais implicam-se umas nas outras em perspectivas intertextuais, nas quais moral, religião, sociologia e antropologia estão imbricadas.

Nesse contexto interdisciplinar, a ciência histórica é apresentada como estudo de causas e de suas hipóteses múltiplas. Simplificar e multiplicar as possibilidades de causas ratifica o aspecto teleológico dessa ciência. Segundo Carr (1987), a existência das causas constrói um padrão coerente para guiar as ações humanas, além de promover o discernimento sobre o que se passa no meio em que o ser humano vive. A averiguação das causas das ações humanas estabelece a competência profissional do historiador, diferenciada e intrinsecamente vinculada aos pressupostos da vida cotidiana.

Na mesma direção, pode-se abordar a perspectiva de Le Goff, na medida em que se apresenta o historiador como construtor do fato histórico. Tal evidência coloca em xeque qualquer abordagem tradicionalista da teoria epistemológica da história. A história se remete às representações ideológicas, mentais e rituais inerentes à constituição de qualquer sociedade civil como prática social. A dinamicidade e a mutabilidade dos fatos e ações observáveis fazem da história uma ciência diferenciada, na qual o imaginário social, o conceito e o conjunto de ideias estabelecem um aporte epistemológico basilar na 
abordagem do objeto da história. Trata-se de fornecer ao imaginário, na forma de memória coletiva, um status de testemunho e de força potencial da história.

No capítulo VIII da obra História e memória (Le Goff, 2003), o conceito de memória é visitado de diferentes maneiras, desde uma retomada dos paradigmas sociais através do tempo, até a reconstrução da etimologia do termo e de sua constante variação. A memória possui um caráter psicológico responsável pela "atualização das impressões dos seres humanos com o passado" (Le Goff, 2003, p. 420). Salienta-se, sobretudo, a busca constante de análise historiográfica dos esquecimentos e dos silêncios que ocorrem durante a história, no intuito de revelar os mecanismos de manipulação coletiva e dominação por meio do poder velado ideologicamente.

O construto teórico do conceito de memória parte da argumentação sobre sua importância mnésica para os povos sem escrita. Por meio de manifestações mnemônicas generativas, os mitos de origem e a cultura cotidiana eram difundidos livremente, com possibilidades de criação do discurso (Le Goff, 2003). Após a aquisição da escrita, o panorama muda em direção à transformação da memória coletiva. Surgem dois elementos culturais novos - a comemoração como celebração de acontecimento memorável e o documento escrito, no processo burocratizante de registro e de institucionalização da memória.

Enquanto para os gregos a memória passa por um processo de laicização constitui apenas fundamento da alma no sentido sensorial - para os medievais a memória consolida o aparato dogmático dos ritos religiosos. O culto cristão é comemoração e a Bíblia o documento monumental por excelência. Na Renascença o termo ganha novos familiares: memorável, memorial, memorialista. Museus nacionais formam as instituições valoradas socialmente na formação dos Estados nacionais, multiplicam-se as comemorações e as bibliotecas ganham relevância graças ao movimento enciclopedista. O monumento aos mortos e a fotografia são as manifestações da memória no paradigma do século XX (Le Goff, 2003).

O autor ainda destaca aspectos da contemporaneidade no que concerne à memória: o processo de informatização na evolução das sociedades e na formação de 
identidades coletivas e individuais. Os computadores são apresentados como ferramentas de difusão e controle da memória, por serem capazes, em sua estrutura, de fornecer entrada e saída de dados, além de internalizar aspectos informativos inalcançáveis à memória biológica.

Por fim, salientam-se também os objetos da memória coletiva e da história durante uma abordagem científica: documento (prova ou evidência escolhida pelo historiador) e monumento (sinal do passado que perpetua a recordação, ligado às estruturas dominantes da sociedade que faz parte). Cabe ao cientista social estabelecer condições de esclarecimento, tanto para o documento, como também para o monumento, a fim de elucidar os parâmetros de produção destes instrumentos e revelar a sociedade da qual faz parte.

\section{Considerações conclusivas}

Considerando o quadro exposto, o presente trabalho se dedicou a uma reflexão sobre aproximações entre a escritura, linguagem e memória partindo de referências supostamente distantes - os princípios da dialética negativa de Adorno, a postura da diferença de Derrida e a criticidade de historiadores contemporâneos perante as instituições de poder nas ciências humanas. Os aportes teóricos partiram de duas dimensões comuns: a viabilização do sujeito enquanto indivíduo único, não dominado pelas regras exteriores a sua consciência social; e o total abandono do processo de padronização e homogeneização do monismo metodológico, baseado na unicidade do real.

Longe da pretensão de esgotamento da temática, vale-se ressaltar a existência de inúmeras aproximações substanciais entre os autores referendados que não foram demonstradas no presente trabalho, sendo algumas dignas de nota alusiva. Torna-se necessário, por isso, pontuar ainda que os enfrentamentos dos textos reproduzidos na tradição retomam os embates aos discursos monolíticos do conhecimento, que se concretizam no que Adorno chama de "abertura" dos discursos representativos (Adorno, 
2009). Tal abordagem assemelha-se à Desconstrução derridiana do texto/discurso socializado. Nessa mesma perspectiva, encontra-se, por exemplo, a “différance" entre força e violência, formação e deformação, objeto e conhecimento. Não por acaso, a interpretação adorniana da formação da identidade subjetiva pode ser apresentada como uma precursora da incondicionalidade do sujeito não-idêntico de Jacques Derrida.

Além disso, Derrida declara abertamente ser herdeiro da Escola de Frankfurt como filósofo defensor da não-identidade, demonstrando em seu projeto de teorização uma preocupação frequente pela reformulação política do sujeito. Destaca-se também a coincidência do contexto histórico dos dois autores, ambos de origem judaica, marcados pela sucessão significativa de exílio e adaptação em diferentes países, o que salienta ainda mais qualquer tentativa de compará-los academicamente.

Partindo dessas análises, pode-se destacar ainda inteligibilidade da história como ciência, encontrando no cientista social a capacidade de revelar situações de constrangimento social, viabilizando a criticidade da sociedade perante suas instituições de poder, sejam elas objetivadas ou idealizadas por mecanismos de opressão ideológica. A necessidade de uma nova erudição histórica perpassa os intentos da negação da tradição em nome da libertação coletiva do método, dos instrumentos e dos problemas investigativos que surgem na eleição dos fatos históricos.

Assim, a escrita incondicionada e indecidível de Derrida, a linguagem mediadora das relações entre sujeito e objeto de Adorno e a abordagem historiográfica da memória promovem, com todas as proporções guardadas em seus domínios de atuação, os alicerces de uma epistemologia das ciências humanas, agregadas em suas especificidades plurais de concepções de conhecimento e das suas investigações científicas. 


\section{Referências}

ADORNO, Theodor. Capitalismo tardio ou sociedade industrial. In: COHN, Gabriel (Org.). Theodor W. Adorno. São Paulo: Ática, 1986.

ADORNO, Theodor. Dialética negativa. Tradução de Marco Antonio Casanova. Rio de Janeiro: Jorge Zahar, 2009.

ADORNO, Theodor. Educação e emancipação. Tradução de Wolfgang Leo Maar. Rio de Janeiro: Paz e Terra, 1995a.

ADORNO, Theodor. Minima moralia. Trad. Luiz Eduardo Bicca.São Paulo: Ática, 1992. ADORNO, Theodor. Os pensadores (Adorno e Horkheimer). São Paulo: Abril Cultural, 1991.

ADORNO, Theodor. Palavras e sinais: Modelos Críticos 2. Tradução de Maria Helena Ruschel. Petrópolis: Vozes, 1995b.

CARR, Edward Hallet. O que é história? São Paulo: Paz e Terra, 1987.

CHARTIER, Roger. O mundo como representação. Estudos Avançados, v.11, n.5, p.173-191, jan./abr., 1991.

DERRIDA, Jacques. A escritura e a diferença. Trad. Maria Beatriz M. N. da Silva; Pedro L. Lopes e Pérola de Carvalho. São Paulo: Editora Perspectiva, 2009

DERRIDA, Jacques.. Espectros de Marx. Trad. Anamaria Skinner. Rio de Janeiro: Relume Dumará, 1994.

DERRIDA, Jacques.. A farmácia de Platão. Trad. Rogério Costa. São Paulo: Editora Iluminuras, 2005.

DERRIDA, Jacques. Margens da filosofia. Trad. Joaquim Torres Costa e Antônio M. Magalhães. São Paulo: Papirus, 1991

DERRIDA, Jacques. Papel-máquina. Trad. Evando Nascimento. São Paulo: Estação Liberdade, 2004.

DERRIDA, Jacques.. Posições. Trad. Tomaz Tadeu da Silva. Belo Horizonte: Editora Autêntica, 2001. 
HORKHEIMER, Max.; ADORNO, Theodor. Dialética do esclarecimento: fragmentos filosóficos. Tradução de Guido Antônio de Almeida. Rio de Janeiro: Zahar, 1985.

JAY, Martin. As Idéias de Adorno. Tradução de Adail U. Sobral. São Paulo: Cultrix; Ed. da USP, 1988.

LE GOFF, Jacques. História e memória. Campinas: Editora da UNICAMP, 2003. 